\title{
CARACTERIZAÇÃO TECNOLÓGICA DE MINÉRIO AURÍFERO SULFETADO COM MATERIAL CARBONOSO
}

\author{
G. P. NERY*, C. ULSEN, D. ULIANA, F. R. COSTA, M. M. M. L. TASSINARI E H. KAHN \\ Escola Politécnica da Universidade de São Paulo. Laboratório de caracterização tecnológica \\ guilherme@lct.poli.usp.br
}

Artigo submetido em novembro/2015 e aceito em dezembro/2015

DOI: $10.15628 /$ holos.2015.3790

\section{RESUMO}

Este trabalho apresenta uma metodologia de caracterização tecnológica de minério aurífero contendo material carbonoso, por meio de separações minerais, seguido de amalgamação e cianetação dos produtos obtidos, e emprego de sistema de análise de imagens (MLA, Mineral Liberation Analyser - FEI) para análise quantitativa das associações do ouro de forma a fornecer subsídio para delimitação de alternativas de processo para pesquisas subsequentes objetivando a mitigação das perdas de ouro. A análise granulométrica mostrou distribuição preferencial do ouro em frações acima de $0,074 \mathrm{~mm}$ e o estudo mineralógico identificou associação mineralógica do ouro predominantemente com sulfetos (64\%). A recuperação do ouro foi de $83,9 \%$, e a da parcela não recuperada, 62,6\% está nas frações finas $(-0,037 \mathrm{~mm})$ forte indicador de perda do ouro adsorvido no material carbonoso.

PALAVRAS-CHAVE: caracterização tecnológica, minérios auríferos, preg robbing

\section{TECHNOLOGICAL CHARACTERIZATION OF GOLD ORE ASSOCIATED WITH SULFIDES WITH PRESENCE OF CARBONACEOUS MATTER}

\begin{abstract}
This work presents a technological characterization methodology of gold-bearing ore associated with sulfides containing carbonaceous material through mineral separation, followed by amalgamation and cyanidation of the products obtained. In addition, the use of an automated image analysis system (MLA, Mineral Liberation Analyser - FEI) provided quantity information gold association in order to delimitate process alternatives for further research aimed at mitigation of
\end{abstract}

the gold losses. The particle size analysis showed preferential distribution of gold above $0.074 \mathrm{~mm}$ fractions and mineralogical study identified gold association predominantly with sulfides (64\%). The recovery of gold was $83.9 \%$, and in the portion not recovery, $62.6 \%$ was in the fine fraction $(-0.037 \mathrm{~mm})$ indicating the gold loss is due to absorption onto the carbonaceous material.

KEYWORDS: ore characterization, gold ore, preg robbing. 


\section{INTRODUÇÃO}

O processamento de metais preciosos, como o ouro, é cada vez mais desafiador. Apesar de ser um bem mineral economicamente viável a baixos teores, sua obtenção passa necessariamente pela otimização dos empreendimentos e pela redução de custos e perdas no processo, de forma a garantir sua viabilidade econômica. Isso se deve à diminuição dos teores nos depósitos, a exploração e explotação de depósitos com maiores complexidades mineralógicas e o preço do ouro, definido pelo mercado financeiro mundial.

Uma infinidade de possibilidades e fenômenos respondem pelo ouro reportado ao rejeito. Um deles é conhecido como preg robbing, e refere-se às perdas de ouro pela adsorção do complexo aurodicianeto da solução cianetada por constituintes do próprio minério. Estes constituintes podem ser matéria carbonosa presente no material lavrado ou mesmo minerais presente no minério, tais como sulfetos ou silicatos (Adams e Burguer, 1998, Goodall e Scales, 2005;).

Foi utilizado um procedimento de caracterização tecnológica (concentração mineral e extração hidrometalúrgica) aliada a rotina automatizada de análise de imagens, com emprego do sistema MLA (Mineral Liberation Analyser) integrado a microscópio eletrônico de varredura (MEV) com detector de dispersão de energia (EDS) (Fandrich et al, 2007, Nery et al, 2015, Ulsen et al, 2013).

A caracterização tecnológica, quando aplicada ao beneficiamento de determinada matéria prima mineral, se volta à avaliação de parâmetros básicos do corpo mineral e de seus constituintes, relacionado às alternativas tecnológicas de processamento destes bens minerais (Sant'Agostino e Kahn, 1997).

O emprego de sistemas de análise de imagens automatizado na indústria mineral já está consolidado devido à grande quantidade de informações obtidas em curto espaço de tempo, a diversidade de aplicações e a grande robustez estatística devido ao alto número de partículas analisadas.

A conjugação desta técnica com rotas tradicionais de caracterização tecnológica contribui para o entendimento do comportamento de determinado material frente aos processos tradicionais de beneficiamento. Como decorrência, são relevantes para a estimativa, ainda que preliminar, das recuperações potenciais e possíveis perdas, possibilitando a proposição de alternativas para mitigação das perdas.

\subsection{Objetivos}

O presente trabalho tem como objetivo verificar as formas de ocorrência do ouro e respectivas perda decorrentes do efeito preg robbing, de forma a fornecer subsídios para a delimitação de alternativas de processo. 


\section{MATERIAL E MÉTODOS}

\subsection{Amostra estudada}

O estudo foi realizado em uma amostra mineralizada a ouro, obtida em campanha de sondagem, como parte do estudo para determinação da perda de ouro decorrente do efeito preg robbing em determinado corpo mineral.

A amostra estudada apresenta teor de ouro de 7,22 ppm (calculado a partir dos produtos obtidos no procedimento estabelecido) e é composta majoritariamente por quartzo, dolomita, pirita, muscovita e grafite (identificados por difração de raios $\mathrm{X}$ ).

\subsection{Procedimento experimental}

O procedimento iniciou-se com a cominuição de todo o material, em britador de rolos, de forma a obter produto passante em $0,6 \mathrm{~mm}$, seguido de homogeneização em pilha alongada e amostragem de cinco alíquotas de $2 \mathrm{~kg}$ perfazendo $10 \mathrm{~kg}$ de material para os estudos.

Com quatro destas alíquotas restantes $(8 \mathrm{~kg})$, realizou-se análise granulométrica, por peneiramento a úmido, em malhas de aberturas nominais de 0,30, 0,21, 0,15, 0,074 e 0,037 mm. Cada fração foi amostrada para análises químicas (dosagem do ouro por fire assay e dosagem do conteúdo de carbono e enxofre).

Cada fração, acima de $0,037 \mathrm{~mm}$, foi direcionada à separação mineral por líquido denso (TBE 2,75 g/cm3), com intuito de concentração dos minerais portadores do ouro, visto que, a própria avaliação quantitativa a ser feita depende de identificação de um número significativo de grãos de ouro (Neumann et al, 2002).

Os produtos flutuados e o passante em $0,037 \mathrm{~mm}$ foram direcionados diretamente à etapa de cianetação. O produto pesado, também amostrado para estudos mineralógicos (MEV/MLA), foi direcionado a etapa de amalgamação; após remoção do amálgama, o resíduo sólido também foi direcionado à cianetação ( $40 \%$ de sólidos, concentração de $2.000 \mathrm{~g} / \mathrm{t}$ de $\mathrm{NaCN}, \mathrm{pH} 11)$. Ao final, a polpa foi filtrada para obtenção do licor e do resíduo sólido, produtos dosados quanto ao teor de ouro.

A alíquota restante $(2 \mathrm{~kg})$ foi direcionada diretamente a etapa de extração hidrometalúrgica, nas mesmas condições da cianetação descritas acima, e em duplicatas, para a obtenção da recuperação potencial. Adicionalmente, o rejeito foi submetido a peneiramento a úmido para dosagem do ouro por fração.

\subsubsection{Microscopia eletrônica e análise de imagens automatizada}

O instrumental analítico foi o equipamento Quanta 600FEG (FEI) com espectrômetro de energia dispersiva (EDS) Quantax 400 (Bruker). As alíquotas do produto afundado caracterizadas foram amostradas em divisor de amostras rotativo para garantir a máxima representatividade das mesmas.

A diferenciação das fases minerais é estabelecida pelos diferentes tons de cinza obtidos nas imagens de elétrons retroespalhados (BSE), tom este que está relacionado com o número atômico 
médio. A composição química das fases encontradas é obtida pelos espectros de raios $X$ característicos coletados.

A identificação dos minerais é feita pela comparação desses espectros coletados com banco de dados das fases minerais, contendo o espectro de raios $X$ relativo a composição química de cada fase, e pela comparação do espectro do banco com o espectro coletado em cada grão (Fandrich et al, 2007)

A rotina de busca do ouro nas partículas portadoras, foi realizada também de forma automatizada, pelo modo SPL_Lt, que consiste na busca de fases minerais de elevando número atômico (tons mais claros no contraste BSE) e para cada imagem que atende aos critérios, somente partículas portadoras das fases presentes nesta faixa serão analisadas por EDS.

\section{RESULTADOS E DISCUSSÃO}

A análise granuloquímica (Tabela 1) indica que a amostra, nestas condições de cominuição, apresenta significativo decréscimo do teor de ouro para os finos, de 9,81 a 1,91 ppm. Acima de $0,074 \mathrm{~mm}$ estão contidos $87,5 \%$ de todo o ouro na amostra. A fração passante em $0,037 \mathrm{~mm}$ apresenta teor de 1,91 ppm e responde por $5,2 \%$ de todo o ouro da amostra.

Tabela 1. Análise granulométrica e distribuição de teores dosados

\begin{tabular}{|c|c|c|c|c|c|c|c|}
\hline \multirow{2}{*}{ Fração (mm) } & \multirow{2}{*}{$\begin{array}{c}\% \text { de } \\
\text { massa }\end{array}$} & \multicolumn{3}{|c|}{ Teores } & \multicolumn{3}{|c|}{ Distribuição (\%) } \\
\hline & & Au (ppm) & $\mathrm{C}(\%)$ & $S(\%)$ & $\mathrm{Au}$ & C & $\mathbf{S}$ \\
\hline$-0,60+0,21$ & 27,6 & 9,81 & 2,47 & 1,21 & 37,5 & 22,9 & 24,3 \\
\hline$-0,21+0,15$ & 19,7 & 8,30 & 2,71 & 1,31 & 22,7 & 17,9 & 18,8 \\
\hline$-0,15+0,074$ & 22,1 & 8,92 & 2,87 & 1,58 & 27,3 & 21,3 & 25,4 \\
\hline$-0,074+0,037$ & 10,8 & 4,85 & 3,36 & 1,63 & 7,3 & 12,2 & 12,8 \\
\hline$-0,037$ & 19,8 & 1,91 & 3,87 & 1,29 & 5,2 & 25,7 & 18,6 \\
\hline Total & 100,0 & 7,22 & 2,98 & 1,37 & 100,0 & 100,0 & 100,0 \\
\hline
\end{tabular}

Já o carbono apresenta comportamento inverso, com aumento de teor para os finos, muito provavelmente decorrente da facilidade de cominuição do material carbonoso. Analogamente, 0 enxofre também apresenta aumento de teor até a fração -0,074+0,037 $\mathrm{mm}$, e abaixo desta, ligeira diminuição.

A separação mineral por líquido denso (Tabela 2) promoveu a concentração de material portador do ouro e permitiu um enriquecimento do produto a ser analisado por MEV/MLA. Tal produto, com 28,4 ppm, responde por $84,6 \%$ do ouro da amostra.

Tabela 2. Separação mineral por líquido denso (TBE $2,75 \mathrm{~g} / \mathrm{cm}^{3}$ )

\begin{tabular}{c|cc|c|cc}
\hline \multirow{2}{*}{ Produtos } & \multicolumn{2}{|c|}{ \% em massa } & \multicolumn{2}{c}{ Teor Au } & \multicolumn{2}{c}{ Distrib. Au (\%) } \\
& Ensaio & amostra & (ppm) & Ensaio & amostra \\
\hline Flutuado & 73,2 & 58,7 & 1,25 & 10,8 & 10,2 \\
Afundado & 26,8 & 21,5 & 28,4 & 89,2 & 84,6 \\
Total $+0,037 \mathrm{~mm}$ & 100,0 & 80,2 & 8,53 & 100,0 & 94,8 \\
\hline
\end{tabular}

O ouro contido no produto flutuado (1,25 ppm, que responde por $10,2 \%$ de todo o ouro da amostra) ocorre associado ao material leve, comumente silicatos, associação menos complexa, quando comparado com as associações do produto afundado, mas possivelmente de ocorrência 
em grãos diminutos (justificado pela baixa densidade) e inclusos nestas partículas, além de possibilidade de associação com material carbonoso, que acarretaria perdas de ouro no rejeito.

A Tabela 3 apresenta a distribuição de ouro nos produtos obtidos (flutuado e afundado da separação mineral, e finos, passante em $0,037 \mathrm{~mm}$ ).

Tabela 3. Distribuição potencial de ouro nos produtos da amalgamação e cianetação

\begin{tabular}{|c|c|c|c|c|}
\hline \multirow{2}{*}{\multicolumn{2}{|c|}{ Produtos }} & \multirow{3}{*}{$\begin{array}{c}\begin{array}{c}\text { Teor } \\
\text { Au (ppm) }\end{array} \\
0,74\end{array}$} & \multicolumn{2}{|c|}{ Distribuição de Au (\%) } \\
\hline & & & ensaio & amostra \\
\hline Flutuado & Solução & & 88,5 & 9,02 \\
\hline \multirow[t]{2}{*}{ Total +0,037 mm } & Resíduo & 0,14 & 11,5 & 1,17 \\
\hline & Total Calculado & 1,26 & 100,0 & 10,2 \\
\hline Afundado & Amálgama & 16,1 & 42,4 & 35,0 \\
\hline \multirow[t]{3}{*}{ Total $+0,037 \mathrm{~mm}$} & Solução & 8,11 & 42,8 & 36,8 \\
\hline & Resíduo & 4,21 & 14,8 & 12,8 \\
\hline & Total Calculado & 28,4 & 100,0 & 84,6 \\
\hline Finos & Solução & 0,76 & 59,3 & 3,11 \\
\hline \multirow[t]{2}{*}{$-0,037 \mathrm{~mm}$} & Resíduo & 0,78 & 40,7 & 2,13 \\
\hline & Total Calculado & 1,91 & 100,0 & 5,25 \\
\hline \multirow{4}{*}{ Total } & Amálgama & 16,1 & 35,0 & 35,0 \\
\hline & Solução & 1,40 & 48,9 & 48,9 \\
\hline & Resíduo & 0,46 & 16,1 & 16,1 \\
\hline & Total Calculado & 7,22 & 100,0 & 100,0 \\
\hline
\end{tabular}

O produto afundado, que responde por $89,2 \%$, do ouro apresenta recuperação potencial na amalgamação de $42,4 \%$. Este ouro está relacionado ao ouro passível de recuperação densitária e possivelmente encaminhado a etapa de cianetação direta. O rejeito desta etapa, sob cianetação, apresenta recuperação potencial de $42,8 \%$ do ouro no ensaio ( $36,8 \%$ do ouro na amostra).

Os finos (passante em 0,037 mm) apresentam recuperação potencial de 59,3\% na cianetação. Tal produto, de menor granulometria, era de se esperar maior recuperação quando comparado com os demais produtos. Estas perdas, pode-se supor, que são decorrentes da adsorção do ouro extraído por cianeto no material carbonoso.

No total, $83,9 \%$ do ouro são potencialmente extraídos por cianetação e amalgamação. Quando confrontado com a extração potencial do ouro por cianetação da alíquota tal qual, obtémse recuperação de $80,3 \%$. A Tabela 4 apresenta a análise granuloquímica do rejeito desse procedimento.

Pode-se verificar distribuição do ouro preponderante nas frações finas ( $62,6 \%$ do ouro na fração $-0,037 \mathrm{~mm}$ ), tal fato é forte indicador de perda do ouro adsorvido no material carbonoso e $19,2 \%$ no material mais grosso (acima de $0,21 \mathrm{~mm}$ ) indicando presença de ouro incluso.

Tabela 4. Análise granuloquímica do resíduo sólido da cianetação direta da amostra tal qual

\begin{tabular}{c|c|c|c}
\hline Fração $(\mathbf{m m})$ & \% de massa & Teor Au (ppm) & Distrib. Au (\%) \\
\hline$-0,60+0,21$ & 27,6 & 1,13 & 19,2 \\
$-0,21+0,15$ & 19,7 & 0,59 & 7,2 \\
$-0,15+0,074$ & 22,1 & 0,54 & 3,7 \\
$-0,074+0,037$ & 10,8 & 0,56 & 62,6 \\
$-0,037$ & 19,8 & 5,13 & $\mathbf{1 0 0 , 0}$ \\
\hline
\end{tabular}


O conhecimento das formas de ocorrência do ouro nos produtos e nas frações granulométricas pode ajudar no entendimento da refratariedade apresentada.

As principais associações do ouro no produto afundado acima de 0,037 mm, foram determinadas pelo perímetro de contato do ouro com outros minerais ou expostos no perímetro das partículas (Figura 1).

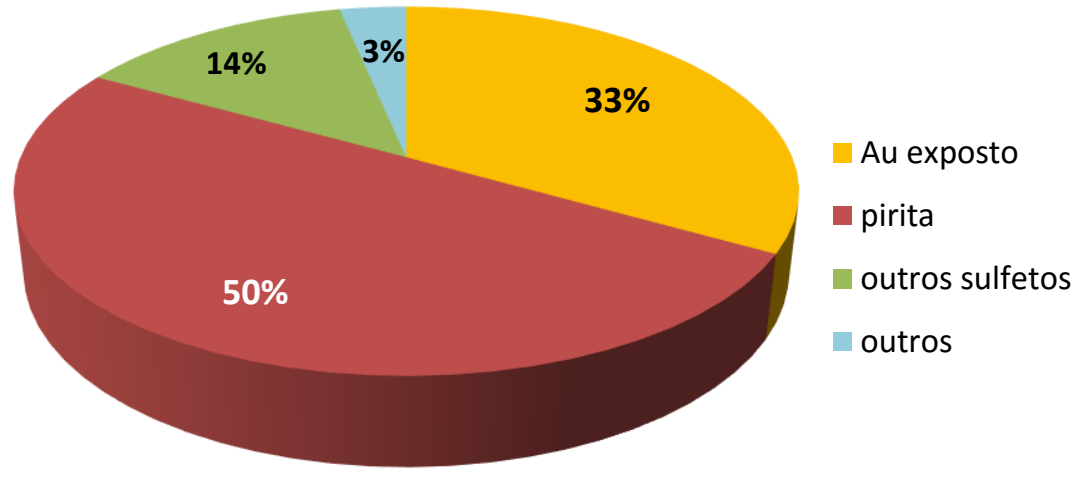

Figura 1. Associações do ouro no produto afundado (total $+0,037 \mathrm{~mm}$ )

O ouro apresenta $33 \%$ de seu perímetro exposto; quando associado a outras fases, encontra-se predominantemente com pirita (50\%) e outros sulfetos ( $14 \%$, esfalerita e galera).

A distribuição acumulada dos grãos de ouro (frequência de partículas ponderadas pela massa; expressa na Figura 2) não segue tendência semelhante às curvas granulométricas, ou seja, frações grossas não necessariamente contém ouro grosso. Verifica-se que $50 \%$ da massa dos grãos de ouro caracterizados, encontram-se entre 30 e $40 \mu \mathrm{m}$ e menos de $10 \%$ em massa ocorre abaixo de $10 \mu \mathrm{m}$.

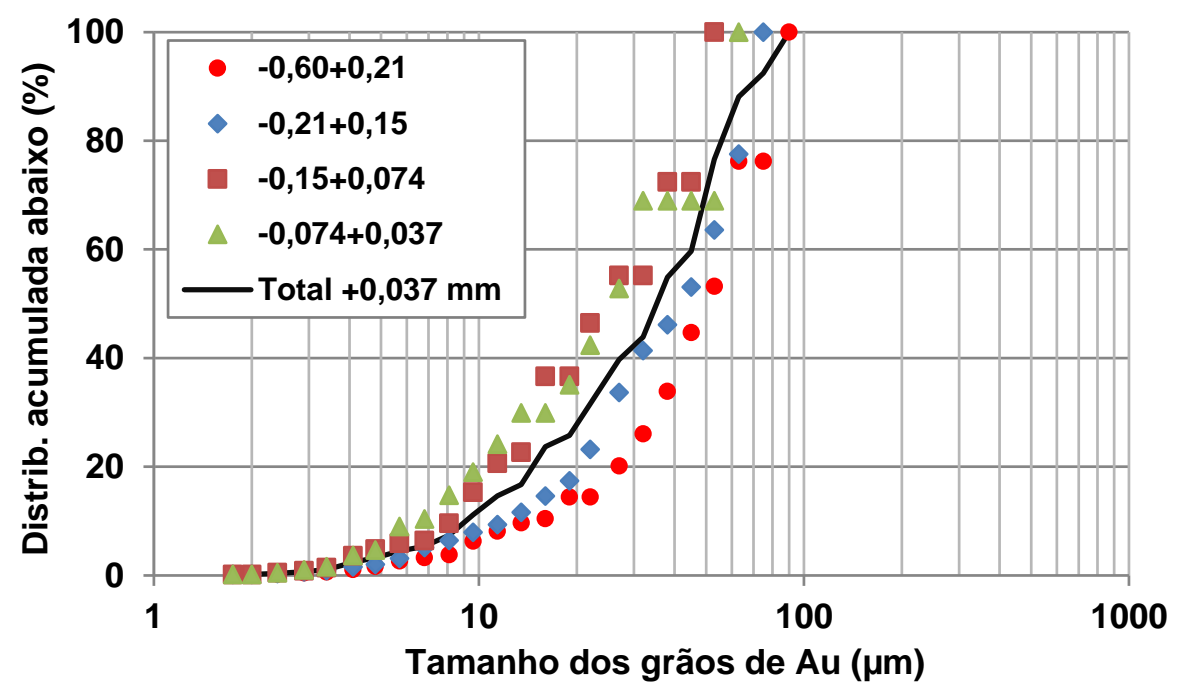

Figura 2. Distribuição do tamanho dos grãos de ouro (total $+0,037 \mathrm{~mm}$ )

\section{CONCLUSÕES}

Pela metodologia exposta foi possível verificar a ocorrência da perda de ouro decorrente do efeito preg robbing e levantar informações pertinentes de forma a delimitar alternativas de processo. 
A distribuição do ouro em granulometrias mais grossas, com baixa associação às gangas leves e passível de recuperação por amalgamação permite supor boa recuperação densitária, principalmente na carga circulante da moagem, exigindo mais estudos de processo.

A ocorrência do ouro, predominantemente exposto ou associado a sulfetos, permite alternativas de concentração do ouro por flotação. Deve-se verificar a possibilidade de flotação desses sulfetos com depressão do material carbonoso.

A parcela refratária (não recuperada por amalgamação ou cianetação) podem ser obtidos em outras condições de cominuição, mas a atenção deve ser redobrada uma vez que moagem mais fina poderá provocar aumento de teor de material carbonoso em granulometria baixa acarretando efeito deletério no processo.

\section{REFERÊNCIAS}

1. Adams, M.D., Burger, A.M., Characterization and blinding of carbonaceous preg-robbers in gold ores. Minerals engineering 10, 1998; 919-927.

2. Fandrich, R., Gu, Y., Burrows, D., Moeller, K., Modern SEM-based mineral liberation analysis. International mineral processing, 84, 2007; 310-320.

3. Goodall, W.R., Leatham, J.D., Scales, P.J., A new method for determination of preg robbing in gold ores. Minerals engineering 18, 2005; 1135-1141.

4. Nery, G., Ulsen, C., Kahn, H., Tassinari, M., \& Uliana, D. (2014). CARACTERIZAÇÃO DE OURO POR ANÁLISE DE IMAGEM AUTOMATIZADA POR FEIXE DE HOLES, HONS. 3, 3-10. doi:http://dx.doi.org/10.15628/holos.2014.1786

5. Neumann, R., Schneider, C.L., Alcover Neto, A., Caracterização de minérios. 4a. ed. Rio de Janeiro: CETEM; 2004. Chapter 3, Tratamento de minérios, p. 55-112.

6. Sant'Agostino, L.M., Kahn, H., Metodologia para caracterização tecnológica de matérias primas minerais. Boletim técnico. Escola Politécnica da Universidade de São Paulo, São Paulo, 1997; 29 p.

7. Ulsen, C., Kahn, H., Nery, G.P., Uliana, D., Antoniassi, J., Gold characterization by MLA and technological tests - discussion of sample preparation and results. In.: 11th International congress of applied mineralogical; 2013. Jul 5-13; Mianyang, China. 